\title{
Outcome and Complications of Combined Modified Deep Sclerectomy and Trabeculectomy for Surgical Management of Glaucoma: A Pilot Study
}

This article was published in the following Dove Press journal: Clinical Ophthalmology

\author{
Tiakumzuk Sangtam (D) ${ }^{1,2}$ \\ Sylvain Roy ${ }^{1,3}$ \\ André Mermoud' \\ 'Glaucoma Center Montchoisi Clinic, \\ Lausanne, Switzerland; ${ }^{2}$ Department of \\ Ophthalmology \& Visual Sciences, Khoo \\ Teck Puat Hospital, Singapore; \\ ${ }^{3}$ Laboratory of Hemodynamics and \\ Cardiovascular Technology, Swiss Federal \\ Institute of Technology, Lausanne, \\ Switzerland
}

\section{Video abstract}

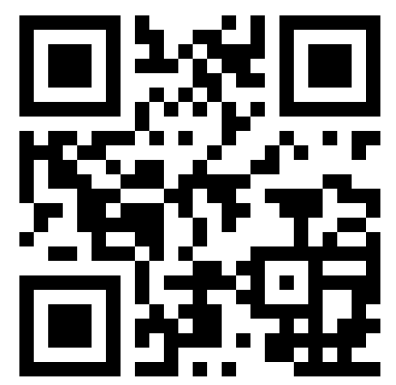

Point your SmartPhone at the code above. If you have a QR code reader the video abstract will appear. Or use: https://youtu.be/a82NJoWmPLg
Correspondence: Tiakumzuk Sangtam Email talk2tiakumzuk@yahoo.co.in
Purpose: To report the outcome and complications of a combined surgical technique of modified deep sclerectomy and trabeculectomy (mDST) for glaucoma.

Patients and Methods: Retrospective study of 44 eyes of 43 patients with open and closed angle glaucoma who underwent mDST. Outcome measures were: Surgical Success with 3 criteria - (i) criterion 1 = intraocular pressure (IOP) $\leq 21 \mathrm{mmHg}$ or reduced by $\geq 20 \%$ of preoperative IOP or IOP $\geq 6 \mathrm{mmHg}$ on 2 consecutive time points after 3 months; (ii) criterion $2=$ IOP $\leq 18 \mathrm{mmHg}$ or reduced by $\geq 30 \%$ of pre-operative IOP or IOP $\geq 6 \mathrm{mmHg}$ on 2 consecutive time points after 3 months and (iii) criterion $3=\mathrm{IOP} \leq 15 \mathrm{mmHg}$ or reduced by $\geq 40 \%$ of preoperative IOP or IOP $\geq 6 \mathrm{mmHg}$ on 2 consecutive time points after 3 months; IOP Reduction; Use of Anti-glaucoma Medication; Complications; Visual Acuity and Postoperative Interventions.

Results: Median follow-up was 40 months (range 24-77 months). At the final follow-up visit, the mean postoperative IOP was $11.5 \pm 4.7 \mathrm{mmHg}(\mathrm{p}<0.0001)$. Mean number of antiglaucoma medications decreased from $2.45 \pm 1.21$ to $0.54 \pm 0.95(\mathrm{p}<0.0001)$. Surgical success in terms of IOP reduction was $50 \% ; 43.2 \% ; 36.4 \%$ for the 3 criteria respectively (complete success) and $70.5 \% ; 56.8 \% ; 47.7 \%$ for the 3 criteria respectively (qualified success). The complications noted were shallow/flat anterior chamber in 2 (4.54\%), hyphema \& bleb leak in $3(6.81 \%)$, aqueous misdirection in $1(2.27 \%)$, hypotonic maculopathy in $2(4.45 \%)$ and hypotony requiring intervention in $6(13.63 \%)$ eyes.

Conclusion: Combined mDST was found to be an effective surgical procedure in reducing IOP. It was associated with complications commonly encountered in glaucoma filtering surgery. The use of intra-scleral space maintainer may help lower the risk of flat or shallow anterior chamber during the early postoperative period.

Keywords: outcome and complications, combined modified deep sclerectomy and trabeculectomy

\section{Introduction}

Trabeculectomy was introduced in 1968 by Cairns $^{1}$ that has become the most commonly performed surgery for glaucoma management. ${ }^{2}$ The initiation of anti-fibrotic usage improved surgical results. ${ }^{3,4}$ However, this was associated with significant complications including hypotony and endophthalmitis. ${ }^{5}$ In an attempt to reduce complications associated with trabeculectomy, non-penetrating deep sclerectomy (NPDS) - by creating an intact trabeculo-Descemetic membrane (TDM) - was popularized as an alternative procedure in the late eighties by Fyodorov and Kozlov. 6,7 NPDS also provides additional aqueous drainage pathways through the intra-scleral 
lake and suprachoroidal space. ${ }^{8,9}$ Nonetheless, a recent metaanalysis ${ }^{10}$ showed NPDS to be less effective in reducing IOP than trabeculectomy for patients with open-angle glaucoma. Moreover, NPDS is a technically more challenging procedure to perform than trabeculectomy. The quest for better and safer surgical techniques continues. We are interested to know whether combining two surgical procedures could provide certain benefits. Herein, we report a pilot study on the surgical outcome and complications of a novel technique combining modified deep sclerectomy and trabeculectomy (mDST) for surgical treatment of glaucoma.

\section{Patients and Methods}

\section{Patients}

Patients who underwent mDST from 2007 to 2012 in Glaucoma Center Montchoisi Clinic, Lausanne, Switzerland were included. Eligibility criteria were: (1) Age $\geq 21$ years (2) Diagnosis of primary or secondary open and closed angle glaucoma (3) Minimum of 2 years follow-up. Informed written consents were obtained before surgery from all the patients and the study was approved by Institutional Review Board and adhered to the tenets of the Declaration of Helsinki.

\section{Pre-Operative Data}

Pre-operative data consisted of patient demographics, the Snellen distance best-corrected visual acuity (BCVA), the highest intraocular pressure (IOP) before surgery measured using a Goldmann applanation tonometer, the number of IOP-lowering medications used at the time of listing for surgery. For patients using topical combinations, the medications were counted according to the number of active drugs. If systemic acetazolamide was used, it was counted as one drug.

\section{Operative Procedures}

One experienced surgeon (AM) performed all the surgeries under retrobulbar anesthesia. A superior corneal traction suture (6-0 Silk, Alcon ${ }^{\circledR}$ Inc) was applied to mobilize the globe for better exposure of the surgical site. Employing a fornix-based approach, limbal peritomy was made for about 3-4 clock hours followed by a proper dissection under the conjunctiva and Tenon's capsule to create a subTenon pouch. Hemostasis was maintained using a mild wet field bipolar cautery. Polyvinyl alcohol sponges soaked in $0.2 \mathrm{mg} / \mathrm{mL}$ Mitomycin-C (MMC) were placed in the pouch, the duration of application depended on the age of the patient and the status of the conjunctiva. The pouch was then thoroughly irrigated with 20 to $30 \mathrm{~mL}$ of balanced salt solution. A $5 \times 5 \mathrm{~mm}$ limbus-based scleral incision was made and a superficial flap of about one-third scleral thickness was fashioned using Crystal-Red sclerectomy knife (Huco ${ }^{\circledR}$ Vision Switzerland). The dissection of the superficial flap was extended $1 \mathrm{~mm}$ further into the clear cornea. A deeper scleral incision of $4 \times 5 \mathrm{~mm}$ with a margin of $0.5 \mathrm{~mm}$ on each side was made with a $25^{\circ}$ Diamond knife (Huco ${ }^{\circledR}$ Vision Switzerland) that was dissected leaving only a very thin layer of deep sclera over the uveal tissue. The deeper dissection was also carefully extended onto the clear corneal stroma to expose the TDM, then the deeper scleral flap was excised. Thereafter, the TDM was punctured and partially excised followed by iridectomy. Intra-operative materials were placed under the flap to act as a space maintainer and offer some resistance to the aqueous flow. The flap was then secured using 10-0 Nylon (Mani ${ }^{\circledR}$ Inc. Japan) with several interrupted sutures to achieve only minimal aqueous ooze. The conjunctiva and Tenon's capsule were closed watertight with one or two running 8-0 Polysorb (Covidien ${ }^{\mathrm{TM}}$ USA).

\section{Intra-Operative Materials}

Different intra-scleral space maintainer used were ophthalmic viscoelastic devices (OVD) such as HealaFlow ${ }^{\circledR}(2.25 \%$ cross-linked sodium hyaluronate), Healon ${ }^{\circledR}$ (1\% sodium hyaluronate) and collagen implants such as Aquaflow ${ }^{\circledR}$ (lyophilized porcine scleral collagen), Ologen ${ }^{\circledR}$ (cross-linked lyophilized porcine type I atelocollagen and glycosaminoglycans). The selection for the type of space maintainer was based on the experience and at the discretion of the surgeon (AM).

\section{Perioperative Data}

The perioperative data obtained were the concentration and duration of MMC application, the type of space maintainer used, the type and method of sutures used to close the scleral flap and the type of anesthesia. Any perioperative complications were noted.

\section{Post-Operative Follow-Up}

Post-operative data included IOP, BCVA and use of IOP lowering medication at 1 day, 1 month, 3 months, 6 months, 12 months, 2 years, and yearly thereafter. Postoperative complications such as bleb leak, hyphema, flat/ shallow anterior chamber, hypotony, choroidal detachment, hypotonic maculopathy, encysted bleb, blebitis, endophthalmitis or others (described in free text) were 
recorded. Any post-operative interventions such as ocular massage, injection of OVD, conjunctiva re-suturing, needling, antimetabolite injection, compression sutures, autologous blood injection, revision for hypotony, and others (described in free text) were also noted.

\section{Outcomes}

The outcome measures were based on the outcome criteria proposed in the World Glaucoma Association Guidelines. ${ }^{11}$ The main outcome measure was the rate of success as defined by the following criteria: (i) criterion $1=$ IOP $\leq 21 \mathrm{mmHg}$ or reduced by $\geq 20 \%$ of pre-operative IOP or IOP $\geq 6 \mathrm{mmHg}$ on 2 consecutive time points after 3 months; (ii) criterion $2=$ IOP $\leq 18 \mathrm{mmHg}$ or reduced by $\geq 30 \%$ of pre-operative IOP or IOP $\geq 6 \mathrm{mmHg}$ on 2 consecutive time points after 3 months and (iii) criterion $3=$ IOP $\leq 15 \mathrm{mmHg}$ or reduced by $\geq 40 \%$ of preoperative IOP or IOP $\geq 6 \mathrm{mmHg}$ on 2 consecutive time points after 3 months. A minimum follow-up of 2 years was included. Surgical success was categorized according to IOP control and the percentage of IOP reduction as detailed above. Due to the retrospective nature of this study, a single IOP measurement was used. Success was further characterized as complete success for those without ocular hypotensive medications and qualified success with ocular hypotensive medications. Failure was defined as (1) IOP measured above the upper limit or below the lower limit $(6 \mathrm{mmHg})$ on 2 consecutive follow-up visits after 3 months (the second consecutive visit was counted as the time of failure). (2) Repeat glaucoma surgery. (3) Loss of light perception vision. However, the use of sub-conjunctival antimetabolite injection, bleb needling, and re-suturing or surgical revision for hypotony was not counted as failures.

\section{Statistical Analysis}

Data were recorded as mean values \pm standard deviation (SD) and ranges (minimum to maximum). Kaplan-Meier survival curve was used to analyze the cumulative probability of success. Student's paired $t$-test was used to assess differences in quantitative variables before and after surgery. A $p$-value of $<0.05$ was considered statistically significant. The data were analyzed using Microsoft Office: mac Excel 2011 and TIBCO Spotfire SPlus 8.1 software.

\section{Results}

\section{Patient Demographics}

There were a total of 44 eyes from 43 patients with 26 females and 17 males. The mean age was $69 \pm 12$ years (range 35-92). The median follow-up was 40 months (range 24-77 months). The demographics of the overall data are shown in Table 1.

Thirty-eight (86.4\%) eyes received MMC except 1 $(2.3 \%)$ who did not get any type of antimetabolite. The concentration of $\mathrm{MMC}$ was $0.2 \mathrm{mg} / \mathrm{mL}$ having a mean exposure time of $1.55 \pm 0.82$ mins. The application of the first sponge was counted as the start of MMC exposure time. There was no information on antimetabolite use in $5(11.4 \%)$ eyes.

Thirty-two $(72.7 \%)$ eyes received $2.25 \%$ cross-linked sodium hyaluronate, $6(13.6 \%)$ eyes received $1 \%$ sodium hyaluronate, $2(4.5 \%)$ eyes received lyophilized porcine scleral collagen, $1(2.3 \%)$ eye received $2.25 \%$ cross-linked sodium hyaluronate + lyophilized porcine scleral collagen, and $1(2.3 \%)$ eye received cross-linked lyophilized porcine type I atelocollagen and glycosaminoglycans. Two (4.5\%) eyes did not receive any intra-scleral space maintainer.

For all eyes having a scleral flap closed with interrupted Nylon ${ }^{\circledR}$ suture, $16(36.4 \%)$ eyes had 8 sutures, 14 $(31.8 \%)$ had 6 sutures, $5(11.4 \%)$ had 9 sutures, $3(6.8 \%)$

Table I Patient Demographics

\begin{tabular}{|l|l|}
\hline Particulars & $\mathbf{n}$ \\
\hline Total eyes (n) & 44 \\
Mean age, years (SD) (range) & $69( \pm \mathrm{I} 2)(35-92)$ \\
Male/Female (n = 43) & $\mathrm{I} / 26$ \\
\hline Race & \\
Caucasian & 38 \\
Blacks & 3 \\
Middle-eastern & 3 \\
\hline Diagnosis & \\
POAG & 25 \\
PACG & $\mathrm{II}$ \\
PEXG & 5 \\
NTG & $\mathrm{I}$ \\
Traumatic glaucoma & $\mathrm{I}$ \\
Aphakic glaucoma & $\mathrm{I}$ \\
\hline Mean preoperative IOP (SD) (range) & $22( \pm 7.07)(\mathrm{II}-40)$ \\
Mean preoperative medications (SD) (range) & $2.45( \pm \mathrm{I} .2 \mathrm{I})(0-5)$ \\
Previous glaucoma surgery & 8 \\
Previous cataract surgery & $\mathrm{I} 2$ \\
Previous glaucoma laser & $0.74( \pm 0.26)(\mathrm{PL}-\mathrm{I} .0)$ \\
Median follow-up, months (range) & \\
Preoperative Snellen BCVA, mean (SD) (range) & $(22-77)$ \\
\hline Note: Preoperative IOP was defned as the inital hig & \\
\hline
\end{tabular}

Note: Preoperative IOP was defined as the initial highest IOP before surgery. Abbreviations: n, numbers; SD, standard deviation; IOP, intraocular pressure; POAG, primary open-angle glaucoma; PACG, primary closed angle glaucoma; PEXG, pseudoexfoliation glaucoma; NTG, normal tension glaucoma; BCVA, bestcorrected visual acuity; PL, perception of light. 
had 7 sutures, 2 (4.5\%) had 10 sutures, 1 (2.3\%) had 2 sutures, $1(2.3 \%)$ had 4 sutures, $1(2.3 \%)$ had 12 sutures and $1(2.3 \%)$ had 8 sutures plus 1 additional releasable suture. None of the eyes had any adjustable sutures.

\section{Intraocular Pressure \& Anti-Glaucoma Medications}

The mean pre-operative IOP was $22.0 \pm 7.1 \mathrm{mmHg}$ (range 11-40). Forty-two (95.5\%) eyes were on antiglaucoma medications before the surgery. The mean preoperative number of anti-glaucoma medications was 2.45 \pm 1.21 (range 0-5). At the final follow-up visit, the mean IOP was $11.5 \pm 4.7 \mathrm{mmHg}$ (range 3-25), representing a decrease of $10.5 \mathrm{mmHg}(-47.9 \%$; $<0.0001)$ between the pre-operative and post-operative IOP. The IOP outcome of eyes at the final follow-up is given in Table 2. The Kaplan-Meier survival curve for the eyes achieving IOP $<21 \mathrm{mmHg}$ and $20 \%$ pre-operative IOP is shown in Figure 1. The mean IOP of eyes over time is depicted as a box-and-whisker plot in Figure 2. A scatter plot comparing pre-operative IOP and post-operative IOP is shown in Figure 3. The mean number of anti-glaucoma medications per patient decreased from $2.45 \pm 1.21$ to $0.54 \pm 0.95$ (range $0-3 ; \mathrm{p}<0.0001$ ) at the final follow-up visit. Thirteen eyes $(29.5 \%)$ required $1-3$ anti-glaucoma medications to control IOP (Figure 4).

There were a total of $27(61.4 \%)$ eyes that had preoperative IOP $<22 \mathrm{mmHg}$. At the final follow-up, 20 (74.1\%) of these eyes had an IOP reduction of $\geq 20 \%$ or more and $14(51.9 \%)$ had IOP reduction of $\geq 30 \%$ or more. Eight out of the total 27 (29.6\%) eyes required hypotensive medication. There were $3(11.1 \%)$ eyes with IOP of $<6$ $\mathrm{mmHg}$.

\section{Visual Acuity}

The mean post-operative Snellen BCVA was $0.73 \pm 0.24$. Twenty-seven (61.4\%) eyes had BCVA within 2 lines of pre-operative visual acuity. Thirteen (29.5\%) eyes had a loss in BCVA. Out of which $6(46.2 \%)$ eyes had $\geq 3$ lines loss, $3(50 \%)$ of them had advanced glaucomatous optic neuropathy (GON). Mean number of Snellen lines loss was $0.26 \pm 0.16$. Ten $(22.7 \%)$ had an improvement in BCVA, of which $4(40 \%)$ had $\geq 3$ lines improvement. None of the patients lost perception of light vision.

\section{Complications}

Intra-operative and postoperative complications are shown in Table 3 . One (2.3\%) eye required revision for early hypotony (within 3 months). Five (11.4\%) had late-onset hypotony between 7 months and the final follow-up that required surgical bleb revision. Four (9.1\%) had an IOP $\leq 5 \mathrm{mmHg}$ at the final follow-up. Two of these 4 eyes lost $\geq 4$ lines in Snellen BCVA, both of which had a pre-existing advanced GON. Three $(6.8 \%)$ eyes had hyphema on the first post-operative day that resolved within 1 month. No intraoperative hyphema was encountered. Three (6.8\%) eyes had bleb leaks, 2 of them occurred within 1 month after surgery and both were sutured. The last one had late-onset (60 months) leak from ischemic/ avascular bleb that required bleb revision surgery.

\section{Interventions}

Post-operative interventions administered from surgery to the final follow-up are shown in Table 4. Bleb needling with MMC injection was done in $22(50 \%)$ eyes. Out of which, $16(72.7 \%)$ eyes received it within the first 6 months. Three vitrectomies were performed ( 1 for aqueous misdirection, 1 for epiretinal membrane and the last 1 for cataract surgery complication - posterior capsule rupture).

\section{Discussion}

This study shows that combined mDST is an effective surgical option to reduce IOP in the management of glaucoma. The combined surgery was performed in patients with different types of glaucoma including primary open-angle glaucoma, pseudoexfoliation glaucoma, angle-closure glaucoma,

Table 2 Outcomes for Success at the Final Follow-Up

\begin{tabular}{|c|c|c|c|}
\hline Parameters & $\begin{array}{l}\text { IOP } \leq \mathbf{2} \text { I } \mathbf{m m H g} \text { or Reduced by } \\
\geq 20 \% \text { of Pre-Operative IOP or IOP } \\
\geq 6 \mathrm{mmHg} \text { on } 2 \text { Consecutive Time } \\
\text { Points After } 3 \text { Months }\end{array}$ & $\begin{array}{l}\text { IOP } \leq 18 \mathrm{mmHg} \text { or Reduced by } \\
\geq 30 \% \text { of Pre-Operative IOP or IOP } \\
\geq 6 \mathrm{mmHg} \text { on } 2 \text { Consecutive Time } \\
\text { Points After } 3 \text { Months }\end{array}$ & $\begin{array}{l}\text { IOP } \leq \text { I } 5 \mathrm{mmHg} \text { or Reduced by } \\
\geq 40 \% \text { of Pre-Operative IOP or IOP } \\
\geq 6 \mathrm{mmHg} \text { on } 2 \text { Consecutive Time } \\
\text { Points After } 3 \text { Months }\end{array}$ \\
\hline Complete success & 22 (50\%) & $19(43.18 \%)$ & $16(36.36 \%)$ \\
\hline Qualified success & $3 \mathrm{l}(70.45 \%)$ & 25 (56.8I\%) & 21 (47.72\%) \\
\hline
\end{tabular}

Note: Success is characterised for all 44 eyes according to IOP criteria and IOP percentage reduction.

Abbreviation: IOP, intraocular pressure. 


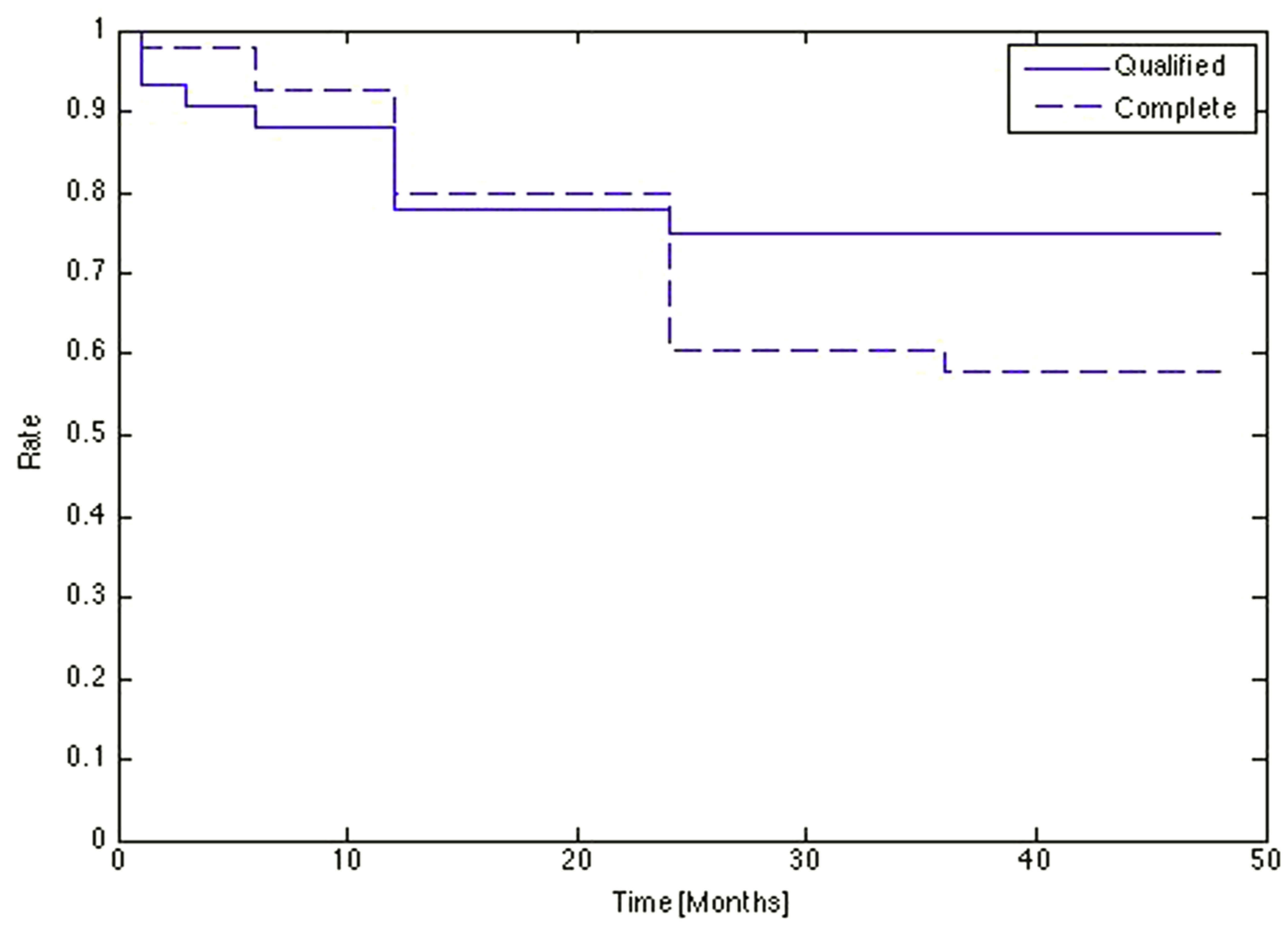

Figure I Kaplan-Meier survival curve showing the cumulative probability of success at 48 months follow-up.

traumatic and aphakic glaucoma with a follow-up of a minimum 24 months. As alluded to earlier, trabeculectomy is the most effective surgical procedure for reducing IOP in patients with open-angle glaucoma. However, it was associated with a higher incidence of complications when compared with NPDS. ${ }^{10,12-14}$ Combining these two surgical procedures appears to provide a comparable result to trabeculectomy in terms of IOP reduction but with a relatively fewer rate of flat or shallow anterior chamber when paralleled retrospectively to published results.

The goal for any glaucoma therapy is the prevention of further glaucomatous optic nerve damage and visual field loss with preservation of visual function. At present, the lowering of IOP remains the only means to achieve this goal. Hence, the most useful measure of the effect of glaucoma surgery is a reduction in IOP. In the present study, the mean postoperative IOP at the final follow-up visits was $11.5 \pm 4.7 \mathrm{mmHg}$, which is comparable to other studies having $13.3 \pm 6.8 \mathrm{mmHg}^{15}$ and $11.4 \pm 6.0 \mathrm{mmHg}^{16}$ after trabeculectomy. The surgical success in terms of IOP reduction achieved in our study was $50 \%$ for criterion 1 ; $43.2 \%$ for criterion $2 ; 36.4 \%$ for criterion 3 (complete success) and $70.5 \%$ for criterion $1 ; 56.8 \%$ for criterion 2 ;
47.7\% for criterion 3 (qualified success). On comparing our results to trabeculectomy, a more reasonable candidate would be the Tube Versus Trabeculectomy (TVT) ${ }^{15}$ study, which had a similar diagnosis profile and criteria for surgical success. In the trabeculectomy arm of TVT, $40 \%$ had complete success and $26 \%$ had qualified success in 3 years follow-up compared to $50 \%$ of complete success and $70.45 \%$ of qualified success at the final follow-up in the present study. In studies comparing NPDS to trabeculectomy, the reported complete success rate varied from $40 \%$ to $79 \%$ in NPDS versus $45 \%$ to $92.6 \%$ in trabeculectomy and the qualified success rate varied from $76.5 \%$ to $95 \%$ in NPDS versus $88.9 \%$ to $95 \%$ in trabeculectomy. ${ }^{12-14,17-19}$ It is difficult to compare different studies and surgical techniques with dissimilar success criteria and diagnosis profile. However, one must remember that all the patients in other studies reported had common features of openangle glaucoma, underwent primary surgery (no previous glaucoma surgery) and varied follow-up periods ranging from 12 months to 48 months. On the other hand, our study had a mixed diagnosis of glaucoma with a follow-up of minimum 24 months. Besides, we had 8 (18.2\%) eyes with previously failed glaucoma surgeries after undergoing 


\section{Mean IOP}

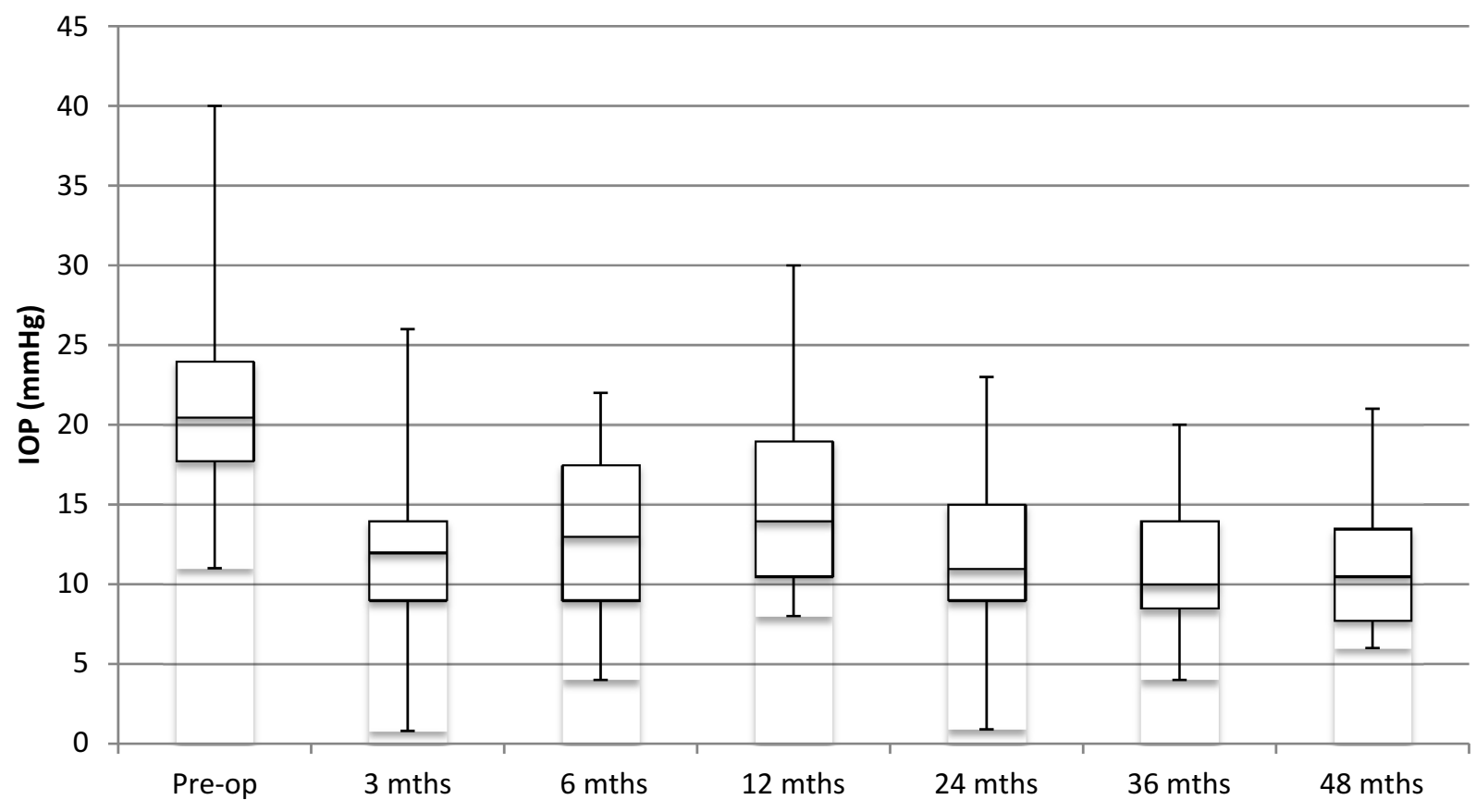

Follow-up time

Figure 2 Box-and-whisker plot showing the changes in mean IOP over time post-operatively.

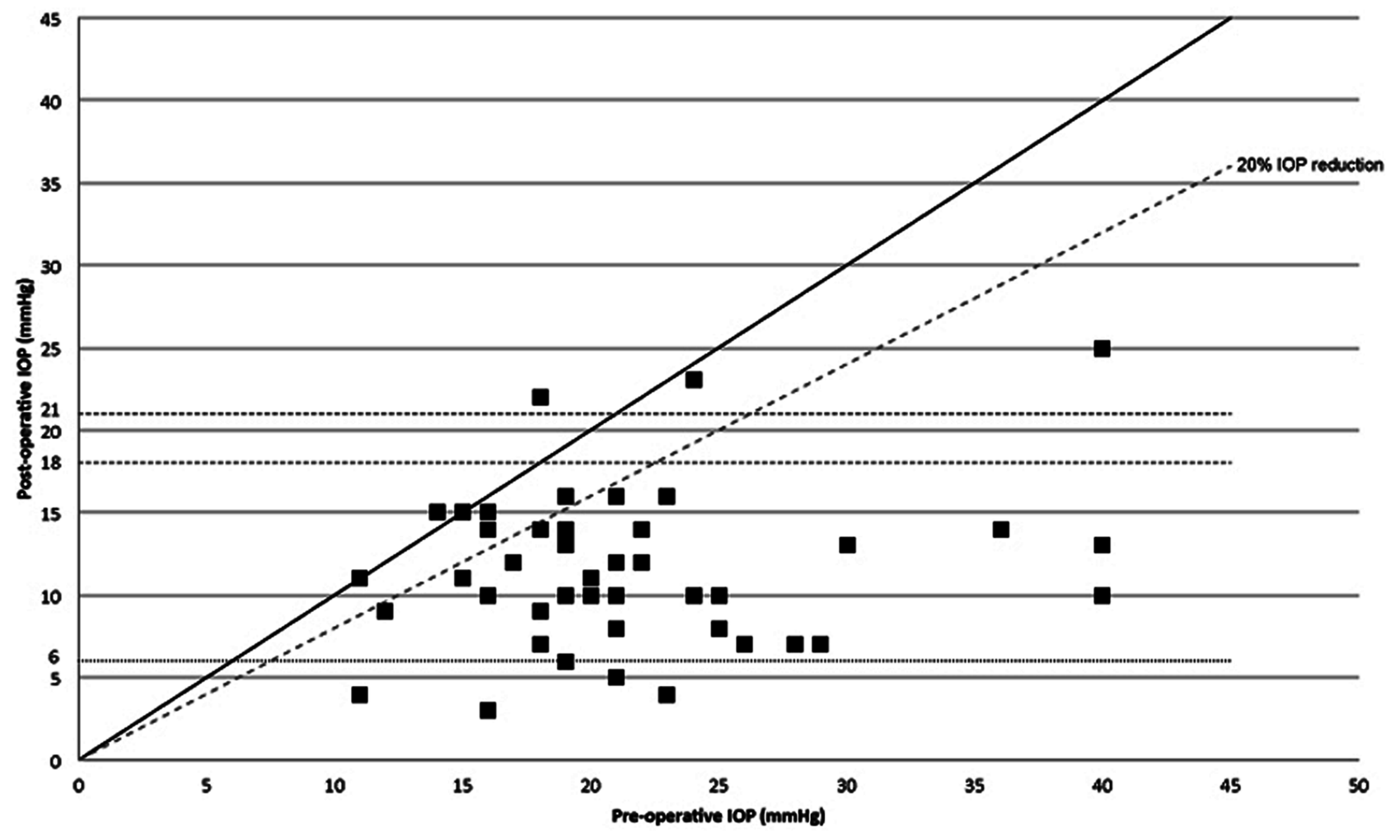

Figure 3 Scatter graph of pre-operative versus post-operative IOP. 


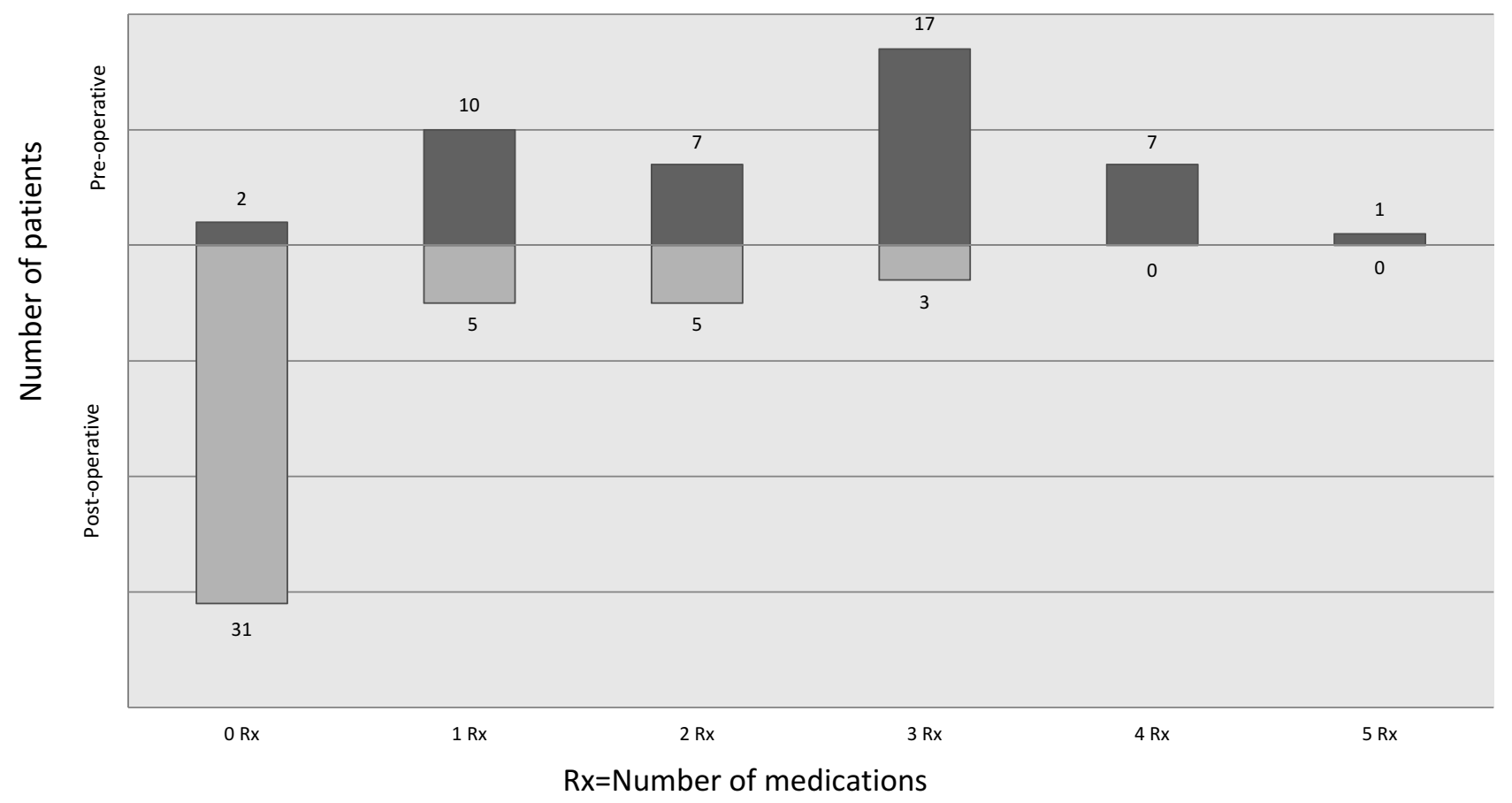

Figure 4 Graph showing number of anti-glaucoma medications per patient before and after surgery.

deep sclerectomy and Ex-PRESS ${ }^{\circledR}$ glaucoma filtration device $\left(\right.$ Alcon $\left.^{\circledR}\right)$. Moreover, the success criteria used in the other studies were different from the current study having more rigorous criteria incorporating both IOP value and percentage reduction. These factors might explain the differences in results seen between our current report and the reports mentioned above.

Two previous studies ${ }^{20,21}$ of combined deep sclerectomy and trabeculectomy have reported a complete success

Table 3 Complications: Intraoperative \& Post-Operative

\begin{tabular}{|l|l|}
\hline Complications & Number \\
\hline Conjunctival button-hole & 0 \\
Flap tear & 0 \\
Posterior capsule rupture & $2(4.54 \%)$ \\
Hyphema & $3(6.81 \%)$ \\
Bleb leak & $3(6.81 \%)$ \\
Shallow anterior chamber & $2(4.54 \%)$ \\
Flat anterior chamber & 0 \\
Choroidal detachment & 0 \\
Iris plug & $1(2.27 \%)$ \\
Aqueous misdirection & $1(2.27 \%)$ \\
Hypotonic maculopathy & $2(4.45 \%)$ \\
Hypotony requiring intervention & $6(13.63 \%)$ \\
Blebitis without endophthalmitis & 0 \\
Bleb related endophthalmitis & 0 \\
Cataract surgery related endophthalmitis & 0 \\
Bleb dysthesia & 0 \\
\hline
\end{tabular}

rate of $83.3 \%$ to $92.2 \%$. However, it should be noted that all their patients underwent primary glaucoma surgery, had a smaller sample (12 and 31 eyes respectively) of solely open-angle glaucoma, and had dissimilar surgical technique and success criteria with one ${ }^{21}$ of the studies having only $8(25.8 \%)$ eyes by the 12-month follow-up and 13 $(41.9 \%)$ eyes requiring post-operative medications. Furthermore, the follow-up period was shorter having a mean duration of 8.3 to 12 months. It must be pointed out that mean duration of 12 months follow-up is comparatively shorter when it is known for success rate to decline with time after filtering surgery. ${ }^{22-24}$ Higher rates

Table 4 Post-Operative Interventions

\begin{tabular}{|c|c|}
\hline Intervention & Number \\
\hline Resuturing for bleb leaks & $2(4.54 \%)$ \\
\hline Bleb needling & $22(50 \%)$ \\
\hline Subconjunctival MMC injection & $22(50 \%)$ \\
\hline Subconjunctival Avastin ${ }^{\circledR}$ (bevacizumab) injection & I (2.27\%) \\
\hline Laser for iris plug & I (2.27\%) \\
\hline Viscoelastic injection & $4(9.09 \%)$ \\
\hline Revision for bleb leak or hypotony & $6(13.63 \%)$ \\
\hline Autologous blood injection & I (2.27\%) \\
\hline Cataract surgery & $12(27.27 \%)$ \\
\hline Vitrectomy & $3(6.81 \%)$ \\
\hline Compression sutures & I (2.27\%) \\
\hline
\end{tabular}

Abbreviation: MMC, Mitomycin-C. 
of shallow anterior chamber were reported in $13 \%{ }^{20,21}$ compared with $4.5 \%$ in our current study. Similarly, $13 \%^{20,21}$ of choroidal detachment was seen compared to nil in our study.

The number of post-operative medications in other studies mentioned earlier ranged from $0.30 \pm 0.40$ to 1.0 \pm 1.0 in NPDS and $0.27 \pm 0.5$ to $1.2 \pm 1.1$ in trabeculectomy. In our study, it was $0.54 \pm 0.95$ which is comparable and lesser than some of the studies mentioned above.

Although NPDS studies did not report any occurrence of flat or shallow anterior chamber, trabeculectomy had a high rate varying from $7.7 \%$ to $33.3 \% .^{12-15,17}$ The incidence was much lower $(4.5 \%)$ in our study. A possible explanation for this lower figure could be due to the use of several intrascleral space-occupying materials along with the application of multiple interrupted sutures to the scleral flap that provided suitable resistance to the aqueous flow. Furthermore, we did not encounter any eye with choroidal detachment $(0 \%)$ when compared to previous reports of $0 \%$ to $5 \%$ in NPDS $^{12,14}$ and $3 \%$ to $30 \%$ in trabeculectomy. ${ }^{14,15}$ Bleb leak was seen in $6.81 \%$ in our study, which is comparable to other studies reporting 2.6 to $12 \%$ in $\operatorname{NPDS}^{13,18}$ and 7 to $12 \%$ in trabeculectomy. ${ }^{12,18}$

Hyphema was seen in $6.81 \%$ in our study compared with 2 to $15 \%$ in $\operatorname{NPDS}^{12,14}$ and 7.7 to $41 \%$ in trabeculectomy. ${ }^{13,18}$ This lower rate could be possibly related to surgical technique and location of anterior chamber entry and iridectomy.

Hypotonic maculopathy was seen in $4.5 \%$ and aqueous misdirection was seen in 1 eye in our study, which is comparable to $4 \%$ and 1 eye respectively in $\mathrm{TVT}^{15}$ study (trabeculectomy arm). The rate of hypotony was $13.6 \%$, which is slightly higher than NPDS $(10 \%)^{14}$ but lower than trabeculectomy (2.6 to $27.8 \%){ }^{13,17}$

There were frequent post-operative interventions in the current study where $50 \%$ had bleb needling done when there were signs of bleb failure as evidenced by increased bleb vascularity with progressive IOP elevation or bleb encapsulation. Overall 13.6\% underwent revision for bleb leak or hypotony. These figures possibly reflect our aggressive and proactive post-operative management in the pursuit of achieving target IOP for each patient.

Fortunately, none of the eyes in our study experienced serious sight-threatening complications such as endophthalmitis compared with 3\% (trabeculectomy group) in TVT study ${ }^{15}$ during the post-operative follow-up ranging from 24-77 months.

The current report has limitations inherent in a retrospective study with a potential loss to follow-up, smaller sample size, non-controlled use of intrascleral space maintainer and that the data relied on past clinical notes. However, it gives us an insight into the ground realities of what could be achieved in our clinical practice with this technique. Moreover, this mDST can be useful to those surgeons who are learning to perform NPDS and transitioning from trabeculectomy to NPDS. Should inadvertent perforation of TDM occur during their NPDS procedure, the surgeon would be able to simply convert the NPDS to mDST.

\section{Conclusions}

Combined mDST is a viable and effective procedure in the surgical reduction of IOP with associated complications commonly seen in glaucoma filtering surgery. The use of intrascleral space maintainer may help provide resistance and modulate aqueous flow that could lower the risk of flat or shallow anterior chamber during the early postoperative period. Further prospective controlled randomized study comparing trabeculectomy with $\mathrm{mDST}$ may be worthwhile to determine its true place in terms of its effectiveness and safety in the armamentarium of glaucoma surgical procedures.

\section{Disclosure}

The authors report no conflicts of interest in this work.

\section{References}

1. Cairns JE. Trabeculectomy. Preliminary report of a new method. Am J Ophthalmol. 1968;66:673-679. doi:10.1016/0002-9394(68)91288-9

2. Ramulu PY, Corcoran KJ, Corcoran SL, Robin AL. Utilization of various glaucoma surgeries and procedures in Medi-care beneficiaries from 1995 to 2004. Ophthalmology. 2007;114:2265-2270. doi:10.1016/j.ophtha. 2007.02.005

3. Chen CW, Huang HT, Bair JS, Lee CC. Trabeculectomy with simultaneous topical application of mitomycin-C in refractory glaucoma. J Ocul Pharmacol. 1990;6:175-182. doi:10.1089/jop.1990.6.175

4. Rothman RF, Liebmann JM, Ritch R. Low-dose 5-fluorouracil trabeculectomy as initial surgery in uncomplicated glaucoma: long-term follow-up. Ophthalmology. 2000;107:1184-1190. doi:10.1016/S01616420(00)00085-3

5. DeBry PW, Perkins TW, Heatley G, et al. Incidence of late- onset bleb-related complications following trabeculectomy with mitomycin. Arch Ophthalmol. 2002;120:297-300. doi:10.1001/archopht.120.3.297

6. Fyodorov SN. Non-penetrating deep sclerectomy in open angle glaucoma [in Russian]. Eye Microsurg. 1989;1:52-55.

7. Kozlov VI, Bagrov SN, Anisimova SY, et al. Deep sclerectomy with collagen [in Russian]. Eye Microsurg. 1990;3:44-46.

8. Chiou AGY, Mermoud A, Underdahl JP, Schnyder CC. An ultrasound biomicroscopic study of eyes after deep sclerectomy with collagen implant. Ophthalmology. 1998;105:746-750. doi:10.1016/S01616420(98)94033-7

9. Kazakova D, Roters S, Schnyder CC, et al. Ultrasound biomicroscopy images: long-term results after deep sclerectomy with collagen implant. Graefe's Arch Clin Exp Ophthalmol. 2002;240:918-923. doi:10.1007/s00417-002-0567-7 
10. Rulli E, Biagioli E, Riva I, et al. Efficacy and safety of trabeculectomy vs nonpenetrating surgical procedures: a systematic review and meta-analysis. JAMA Ophthalmol. 2013;131:1573-1582. doi:10.1001/ jamaophthalmol.2013.5059

11. Heuer DK, Barton K, Grehn F, et al. Consensus on definitions of success. In: Shaarawy TM, Sherwood MB, Grehn F, editors. World Glaucoma Association Guidelines on Design and Reporting of Glaucoma Surgical Trials. Amsterdam, The Netherlands: Kugler; 2009:15-24.

12. Mermoud A, Schnyder CC, Sickenberg M, et al. Comparison deep sclerectomy with collagen implant and trabeculectomy in open-angle glaucoma. J Cataract Refract Surg. 1999;25:323-331. doi:10.1016/ S0886-3350(99)80079-0

13. El Sayyad F, Helal M, El-Kholify H, et al. Nonpenetrating deep sclerectomy vs trabeculectomy in bilateral primary open-angle glaucoma Ophthalmology. 2000;107:1671-1674. doi:10.1016/S0161-6420(00) 00263-3

14. Ambresin A, Shaarawy T, Mermoud A. Deep sclerectomy with collagen implant in one eye compared with trabeculectomy in the other eye of the same patient. J Glaucoma. 2002;214-220. doi:10.1097/00061198-200206000-00009

15. Gedde SJ, Schiffman JC, Feuer WJ, Tube Versus Trabeculectomy Study Group, et al. Three-year follow-up of the Tube Versus Trabeculectomy Study. Am J Ophthalmol. 148;2009:670-684. doi:10.1016/j.ajo.2009.06.018

16. Law SK, Shih K, Tran DH, et al. Long-term outcomes of repeat vs initial trabeculectomy in open-angle glaucoma. Am J Ophthalmol. 2009;148:685-695. doi:10.1016/j.ajo.2009.05.032

17. Cillino S, Di Pace F, Casuccio A, et al. Deep sclerectomy vs punch trabeculectomy with or without phacoemulsification: a randomized clinical trial. J Glaucoma. 2004;13:500-506. doi:10.1097/01. ijg.0000137869.18156.81
18. Chiselita D. Non-penetrating deep sclerectomy vs trabeculectomy in primary open-angle glaucoma surgery. Eye. 2001;197-201. doi:10. 1038/eye. 2001.60

19. Russo V, Scott IU, Stella A, et al. Nonpenetrating deep sclerectomy with reticulated hyaluronic acid implant vs punch trabeculectomy: a prospective clinical trial. Eur J Ophthalmol. 2008;18:751-757. doi:10.1177/112067210801800515

20. Kayikcioglu OR, Emre S, Kaya Z. Trabeculectomy combined with deep sclerectomy and scleral flap suture tension adjustment under an anterior chamber maintainer: a new modification of trabeculectomy. Int Ophthalmol. 2010;30:271-277. doi:10.1007/s10792-009-9326-7

21. Chihara E, Okazaki K, Takahashi H, et al. Modified deep sclerectomy (D-lectomy MMC) for primary open-angle glaucoma: preliminary results. J Glaucoma. 2009;18:132-139. doi:10.1097/IJG.0b013e $3181752 \mathrm{cc} 8$

22. Gedde SJ, Schiffman JC, Feuer WJ, Tube vs Trabeculectomy Study Group, et al. Treatment outcomes in the tube vs trabeculectomy (TVT) study after five years of follow-up. Am J Ophthalmol. 2012;153:789-803. doi:10.1016/j.ajo.2011.10.026

23. The Fluorouracil Filtering Surgery Group. Five-year follow-up of the fluorouracil filtering surgery study. Am J Ophthalmol. 1996;121: 349-366. doi:10.1016/S0002-9394(14)70431-3

24. The Advanced Glaucoma Intervention Study (AGIS): 11. Risk factors for failure of trabeculectomy and argon laser trabeculoplasty. Am $J$ Ophthalmol. 2002;134:481-498. doi:10.1016/S0002-9394(02)016 58-6
Clinical Ophthalmology

\section{Publish your work in this journal}

Clinical Ophthalmology is an international, peer-reviewed journal covering all subspecialties within ophthalmology. Key topics include: Optometry; Visual science; Pharmacology and drug therapy in eye diseases; Basic Sciences; Primary and Secondary eye care; Patient Safety and Quality of Care Improvements. This journal is indexed on PubMed

\section{Dovepress}

Central and CAS, and is the official journal of The Society of Clinical Ophthalmology (SCO). The manuscript management system is completely online and includes a very quick and fair peer-review system, which is all easy to use. Visit http://www.dovepress.com/ testimonials.php to read real quotes from published authors. 